lactic surgery, but that two companies also gave credit for enrolment on a mammographic surveillance programme. Another company reported that this will be part of a review of policy, and in future it may also credit mammographic surveillance. The variation in the industry's responses show that women with a family history who are offered a high rating by one company may receive a lower rating if they approach a second company.

No respondent said that they would request further family history to see if second degree relatives were affected. Disclosure of more cases of cancer in second degree relatives could considerably increase the assessed risk. The artificial nature of the survey might have implied, however, that no further family history existed to be disclosed, so we cannot comment on whether second degree relative information would be requested in reality. How access to adverse test results for BRCA1 or BRCA2 would influence the response to a similar survey in the future remains to be seen.

We thank the life insurance companies for participating in the study, and Adam Butterworth, Cambridge Genetics Knowledge Park, and Alan Tyler, independent insurance and health consultant, for advice and review of the manuscript.

Contributors: AH designed the study with advice from $\mathrm{SEH}$, and did the survey. AH wrote the paper. Both authors critically revised the paper. $\mathrm{SEH}$ is guarantor.

Funding: London IDEAS Genetics Knowledge Park grant, funded by the Departments of Health, and Trade and Industry. Competing interests: None declared.

Ethics approval: Not needed.

\section{What is already known on this topic}

Insurers currently do not use adverse predictive test results for BRCA1 and BRCA2 genes, but this could change and could affect an increasing number of women because of the National Institute for Health and Clinical Excellence's 2004 guidelines recommending genetic testing for certain women at high risk

Applicants must disclose family history to inform risk assessment, but they can also disclose other relevant medical information, such as preventive surveillance or surgery that they may have taken

\section{What this study adds}

Reassuringly, the UK insurance industry currently makes an appropriate assessment of women with a family history of breast cancer, including how preventive action affects risk

Department of Health, Association of British Insurers. Concordat and moratorium on genetics and insurance. London: Department of Health, 2005.

2 Collaborative Group on Hormonal Factors in Breast Cancer. Familial breast cancer: collaborative reanalysis of individual data from 52 epidemiological studies including 58,209 women with breast cancer and 101,986 women without the disease. Lancet 2001;358::1389-99.

3 Tabar L, Yen MF, Vitak B, Chen HH, Smith RA, Duffy SW. Mammography service screening and mortality in breast cancer patients: 20-year follow up before and after introduction of screening. Lancet 2003:361:1405-10.

4 National Institute for Clinical Excellence. Clinical guidelines for the classification and care of women at risk of familial breast cancer. London: NICE 2004.

Rebbeck TR, Friebel T, Lynch HT, Neuhausen SL, van’t Veer L, Garber JE, et al. Bilateral prophylactic mastectomy reduces breast cancer risk in BRCA1 and BRCA2 mutation carriers: the PROSE study group. J Clin Onc 2004;22:1055-62

(Accepted 8 November 2005)

\title{
Severe placental malaria and maternal shortness, thinness, and small skeletal size in rural Congo: cohort study
}

\author{
Hermione J Lovel, Rachel M Newby, Valerie F Hillier
}

Despite global partnerships that aim to eradicate malaria, few studies have investigated susceptibility to severe placental malaria infection (apart from in primigravida ${ }^{1}$ ). Reduced fetal growth ${ }^{1}$ and maternal anaemia sequelae ${ }^{2}$ are known, however, to have serious consequences. We measured mothers at antenatal booking and later explored severe placental malaria as part of a study on factors affecting fetal growth.

\section{Participants, methods, and results}

We investigated a cohort of 436 consecutive rural Bantu women with a singleton pregnancy, with a gestation of less than 24 weeks at booking (determined by ultrasonography), and planning to deliver in Kasaji Hospital in this remote but settled rural area of Katanga province in the Democratic Republic of Congo. A third $(31 \%, 135)$ were primigravida. ${ }^{3}$ RMN followed them all through pregnancy to delivery, between 1996 and 1998 (unaware of their placental malaria status at this stage). RMN took placental impression smears using a rigorous protocol. HC later examined them and counted parasites per field (without antenatal measurements) at the Tropical Diagnostic Laboratory (Dublin). RMN graded parasite density $(0=$ no parasites in 150 fields; $1=1-49$ parasites per 50 fields; $2=$ more than 50 parasites per 50 fields). Because supplies were limited, women were not given chemoprophylaxis for malaria, but prompt treatment with chloroquine was available for symptoms. We found placental infection in 322 women (74\%; 125 (93\%) primigravida, 197 (65\%) multigravida; and 85 (58\%) gravida six or more), mainly Plasmodium falciparum.

Women later found to have severe (grade 2) placental malaria were shorter and thinner at booking than those with no placental malaria (table 1; statistically significant decreasing gradient with placental malaria severity groups; analysis of variance $\mathrm{P}<0.05$ ), for three measures of skeletal smallness (height, interiliac crests, and intergreater trochanters) and three measures of thinness (body mass index, midarm circumference, and weight). Foot size and triceps skinfold thickness showed similar but non-significant trends.
WHO Collaborating Care, School of Primary Care, University of Manchester, Rusholme Health Centre, Manchester M14 5NP

Hermione J Lovel senior lecturer

Katanga Province, DR Congo Kasaji Hospital Rachel M Newby midwife

Division of Imaging Science and Biomedical

Engineering, University of Manchester, Manchester M13 9PL Valerie F Hillier senior lecturer

Correspondence to: HJ Lovel hlovel04@ yahoo.co.uk

BMJ 2005;331:1439-40 
Maternal measurements at the antenatal booking clinic by grade of placental malaria*

\begin{tabular}{|c|c|c|c|c|}
\hline \multirow[b]{2}{*}{$\begin{array}{l}\text { Maternal measurement at } \\
\text { antenatal booking }\end{array}$} & \multicolumn{3}{|c|}{ Grade } & \multirow[b]{2}{*}{$P$ value } \\
\hline & $\begin{array}{l}0 \text { (non-infected } \\
\text { placenta) }\end{array}$ & $\begin{array}{l}1 \text { (infected } \\
\text { placenta) }\end{array}$ & $\begin{array}{l}2 \text { (infected } \\
\text { placenta) }\end{array}$ & \\
\hline \multicolumn{5}{|l|}{ Height (cm) } \\
\hline No & 111 & 176 & 139 & \\
\hline Median & 155.0 & 154.5 & 153.0 & \\
\hline Mean (standard deviation) & $155.1(6.2)$ & $154.7(6.2)$ & $153.2(6.5)$ & $P \leq 0.020$ \\
\hline
\end{tabular}

\begin{tabular}{lcccc} 
Interiliac crests $(\mathrm{cm})$ & & & & \\
\hline No & 98 & 150 & 113 & \\
\hline Median & 24.8 & 24.5 & 24.0 & \\
\hline Mean (standard deviation) & $24.7(1.6)$ & $24.5(1.5)$ & $24.0(1.5)$ & $\mathrm{P} \leq 0.001$ \\
\hline
\end{tabular}

Inter-greater trochanter $(\mathrm{cm}) \quad 24.7(1.6) \quad 24.5(1.5) \quad 24.0(1.5) \quad \mathrm{P} \leq 0.001$

\begin{tabular}{lcccl}
\hline No & 98 & 150 & 113 & \\
\hline Median & 27.8 & 27.3 & 27.0 & \\
\hline Mean (standard deviation) & $27.6(1.8)$ & $27.4(1.6)$ & $26.9(1.5)$ & $P \leq 0.002$ \\
\hline Foot
\end{tabular}

\section{Foot size (Clarks' foot gauge)}

\begin{tabular}{lcccl}
\hline No & 98 & 153 & 116 & \\
\hline Median & 5.0 & 5.0 & 4.5 & \\
\hline Mean (standard deviation) & $4.9(1.5)$ & $4.9(1.5)$ & $4.5(1.6)$ & $P \geq 0.060 \ddagger$ \\
\hline Weight $(\mathrm{kg})$
\end{tabular}
Weight (kg)

\begin{tabular}{lccc}
\hline No & 114 & 177 & 140 \\
\hline Median & 49.8 & 49.3 & 47.1 \\
\hline
\end{tabular}

\begin{tabular}{lllll}
\hline Mean (standard deviation) & $51.2(8.4)$ & $50.0(7.4)$ & $48.0(6.6)$ & $\mathrm{P} \leq 0.001$ \\
\hline
\end{tabular}
Mid-arm circumference (mm)

\begin{tabular}{lcccl}
\hline No & 113 & 177 & 140 & \\
\hline Median & 244 & 238 & 232 & \\
\hline Mean (standard deviation) & $249(27)$ & $243(23)$ & $235(21)$ & $P \leq 0.001$ \\
\hline
\end{tabular}

Triceps skinfold (mm)

\begin{tabular}{lcccl}
\hline No & 55 & 107 & 69 & \\
\hline Median & 11.6 & 11.3 & 11.2 & \\
\hline Mean (standard deviation) & $12.6(4.6)$ & $11.9(3.9)$ & $11.4(3.4)$ & $P \geq 0.270 \ddagger$ \\
\hline
\end{tabular}

\begin{tabular}{lcccc} 
Mean (standard deviation) & $12.6(4.6)$ & $11.9(3.9)$ & $11.4(3.4)$ & $P \geq 0.270 \ddagger$ \\
\hline Body mass index $\left(\mathrm{kg} / \mathrm{m}^{2}\right)$ & & & & \\
\hline No & 111 & 176 & 139 & \\
\hline Median & 20.8 & 20.6 & 20.0 & \\
\hline
\end{tabular}

\begin{tabular}{lllll}
\hline Mean (standard deviation) & $21.3(2.7)$ & $20.8(2.3)$ & $20.4(2.2)$ & $\mathrm{P} \leq 0.006$
\end{tabular}

All variables were tested and all except height and triceps skinfold showed non-normal distributions, log transformation was not successful so non-parametric statistics were used.

${ }^{\star} 0=$ no parasites in 150 fields; $1=1-49$ parasites per 50 fields; $2=$ more than 50 parasites per 50 fields. tOne way (denotes parametric test, equal variances) analysis of variance (for three groups) or

Joncheere-Terpstra for non-parametric variables. $\ddagger$ Not significant.

Logistic regression using these continuous variables and comparing grade 0 with grade 2 placental malaria showed that only $63 \%$ (131 of the 204 complete cases analysed) of women correctly allocated to the grades, with mid-arm circumference the most important variable, indicating that additional variables also need consideration. None the less, we found the highest frequency of severe placental malaria (36/83, $43 \%)$ with combined shortness $(<155 \mathrm{~cm})$ and thinness (body mass index $<19.8 \mathrm{~kg} / \mathrm{m}^{2}$ ); intermediate rates in women shorter but fatter $(54 / 154,35 \%)$ or

\section{What is already known on this topic}

Severe placental malaria is associated with primigravida

\section{What this study adds}

Maternal shortness ("stunting"), and small skeletal size and thinness ("wasting") are associated with a greater likelihood and severity of placental malaria; the dose-response relationship indicates a causative biological mechanism taller but thinner $(20 / 65,31 \%)$; and the lowest rates $(29 / 124,23 \%)$ in taller fatter women $\left(\chi^{2}\right.$ for the trend $\mathrm{P}<0.01)$.

\section{Comment}

Both shortness and skeletal smallness and thinness are associated with increased likelihood and severity of placental malaria. The severity of placental malaria could be influenced by effects of the immune system in early life and childhood, leading to stunting, probably reflecting poor nutrition and family poverty in childhood. Studies in Gambia show that nutritional programming in fetal and early life may compromise the immune system in a way that only becomes apparent in adult life. ${ }^{4}$ This susceptibility combined with a currently depressed immune system due to current undernutrition could explain the higher rates for short thin pregnant women.

Few other studies have been found, height measurement may lack placental severity information, ${ }^{5}$ or placental severity subjects were recruited only at delivery. ${ }^{1}$ However, increased rates of severe placental malaria were found with rural maternal residence, as well as the primigravid. ${ }^{1}$ If the rural population in Gambia were shorter than the urban population, the data would confirm our observations in Congo.

Would triaging prophylaxis to the short and thin at pregnancy booking be better than the current treatment only protocol to reduce prevalence of severe placental malaria?

Contributors: All the authors designed the study after a pilot investigation by RMN, supervised by HJL. RMN collected the data. All authors, with extensive statistical input from VFH, analysed the data. RMN developed an early draft to which all authors contributed. HJL developed this topic separately and wrote the paper. Hilary Cran, Tropical Diagnostic Laboratory, Dublin, examined the placental slides. Bernard Brabin, Liverpool School of Tropical Medicine; Jason Gardosi, Perinatal Unit, Birmingham; Caroline Fall and Clive Osmond at the Medical Research Council Environmental Epidemiology Unit, Southampton; Henry Kitchener, Department of Obstetrics and Gynaecology, University of Manchester; and Ann Thomson, School of Nursing and Midwifery, University of Manchester; gave valuable input. HJL is guarantor.

Funding: ACE Trust, Dublin, funded the microscopy. RMN was funded by the University of Manchester Scholarship Fund and the British Commonwealth Nurses War Memorial Fund.

Competing interests: None declared.

Ethical approval: Kasaji Hospital, Congo. Also, the University of Manchester ethically inspected the protocol in 1994-5; at that time separate approval was not needed.

1 McGregor IA, Wilson ME, Billewicz WZ. Malaria infection of the placenta in the Gambia, West Africa: its incidence and relationship to stillbirth, birthweight and placental weight. Trans R Soc Trop Med Hyg 1983;77:23244.

2 Matteelli A, Donato F, Shein A, Muchi JA, Leopardi O, Astori L, et al Malaria and anaemia in pregnant women in urban Zanzibar, Tanzania. Ann Trop Med Parasitol 1994:88:475-83.

3 Newby RM. Symphysis-fundal height and the influence of placental malaria and poverty on pregnancy outcomes in rural Democratic Republic of Congo. PhD thesis. Manchester: School of Primary Care, University of Manchester, 2000.

4 Moore SE. Nutrition, immunity and the fetal and infant origins of disease hypothesis in developing countries. Proc Nutr Soc 1998;57:241-7.

5 Reinhardt MC, Ambroise-Thomas P, Cavallo-Serra R, Meylan C, Gautier R. Malaria at delivery in Abidjan. Helv Paediatr Acta Suppl 1978;(41):6584.

(Accepted 8 October 2005) 